\title{
Biliary cancer risk should be kept in mind in laparoscopic surgery for adult choledochal cyst
}

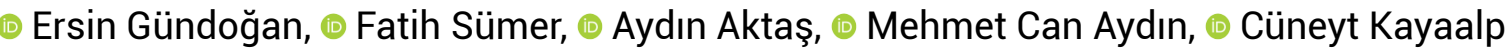 \\ Department of General Surgery, İnönü University Faculty of Medicine, Malatya, Turkey
}

\begin{abstract}
Choledochal cysts are a congenital pathology with a malignant potential that increases with age. The preferred treatment is surgical excision in all age groups, and is now often performed laparoscopically. The aim of this case report was to emphasize the importance of biliary tumor risk when laparoscopic excision of a choledochal cyst is performed in adults. A 46-year-old woman was referred to the clinic for a type 1 choledochal cyst with an accompanying gallbladder polyp with regular margins. She had not had previous abdominal surgery and there were no co-morbidities. The patient underwent a laparoscopic cyst excision, cholecystectomy, and hepaticojejunostomy. The hepaticojejunostomy failed and the procedure was completed by converting to open surgery. The gallbladder and choledochal cysts were removed through an abdominal incision. A specimen pathology report indicated gallbladder cancer (T2NOMO). One month later, a gallbladder bed resection and perihilar lymph node dissection were performed. No malignancy was detected in the second pathology specimen. Follow-up at the postoperative $16^{\text {th }}$ month revealed no difficulties. A literature review of 231 adult laparoscopic choledochal cyst excisions yielded a $2.6 \%$ risk for biliary cancers. Especially in adults, biliary tumors are more commonly associated with choledochal cysts. The cancer risk should not be forgotten during laparoscopic surgery for congenital choledochal cysts.
\end{abstract}

Keywords: Bile-duct cancer; cholecystectomy; choledochal cyst; gallblader carcinoma; hepaticojejunostomy; minimal invasive surgery.

\section{Introduction}

Choledochal cyst is a congenital disease with cystic dilatation of the bile ducts. It is often found in the first decade, but in recent years the incidence is increasing in older ages. ${ }^{[1]}$ It is seen about 10 times more in Asian societies than others. Todani et al. ${ }^{[2]}$ the cyst is divided into 4 types according to the location and dilatation type. While ultrasound is used as the first test at diagnosis, Magnetic resonance cholangiopancreatography is used as the most sensitive technique. Its complications are cholelithiasis, hepatolithiasis, intrahepatic abscess, secondary bile cirrhosis, portal hypertension and biliary cancer. The biliary cancer can develop from the cyst $(50 \%)$, gallbladder (48\%) or intrahepatic bile ducts (2\%).

${ }^{[3]}$ Surgical excision is the accepted treatment for most choledochal cysts.

In this case report, our aim was; to present an adult patient who underwent laparoscopic choledochal exicision because of choledochal cyst and subsequently detected a gallblader cancer. 


\section{Case Report}

A 46-year-old woman without any comorbidities was referred us because of the gallbladder polyp and type 1 choledochal cyst. There was no pathology in the physical examination of the abdomen and laboratory test. In MR cholangiography; a $3 \times 3.5 \times 5 \mathrm{~cm}$ benign looking like polyp in the gallbladder and a dilatation up to $26 \mathrm{~mm}$ in the choledochus was detected (Fig. 1). Laparoscopic surgery was planned and the patient was evaluated as ASA 1. In laparoscopic exploration, the gall bladder was in normal appearance and the polyp inside was felt as mobile. No lymph node or organ invasion were detected in laparoscopic exploration. Laparoscopic choledochal cyst excision, cholecystectomy and hepaticojejunctomy were performed. However; a bilier leak was found in the hepaticojejunostomy line at the end of surgery and convertion to open surgery was throught to be necessary. The bile leak was seen posteriorly on anastomosis line, supportive sutures were placed and the operation was terminated. The specimen was removed from the laparotomy incision. On the macroscopic examination of the gall bladder, there was no problem with serosa and the polyp was palpable in the sac. Postoperatively, the pathologic report of the patient who was discharged without any complaints revealed a $6 \mathrm{~cm}$ sized, moderately differentiated adenocarcinoma in the gallbladder localization. It was reported that the tumor spread to the perimuscular tissue, there was no peritoneal perforation and lymph node spread (T2NOMO Stage 2). One month after the first operation, the patient underwent gallbladder bed resection and lymph node dissection. The patient was discharged without any problems on the eighth day after the second operation. No tumoral foci were detected in the second operative pathology. The patient continues to have a problem-free life at postoperative $16^{\text {th }}$ month.

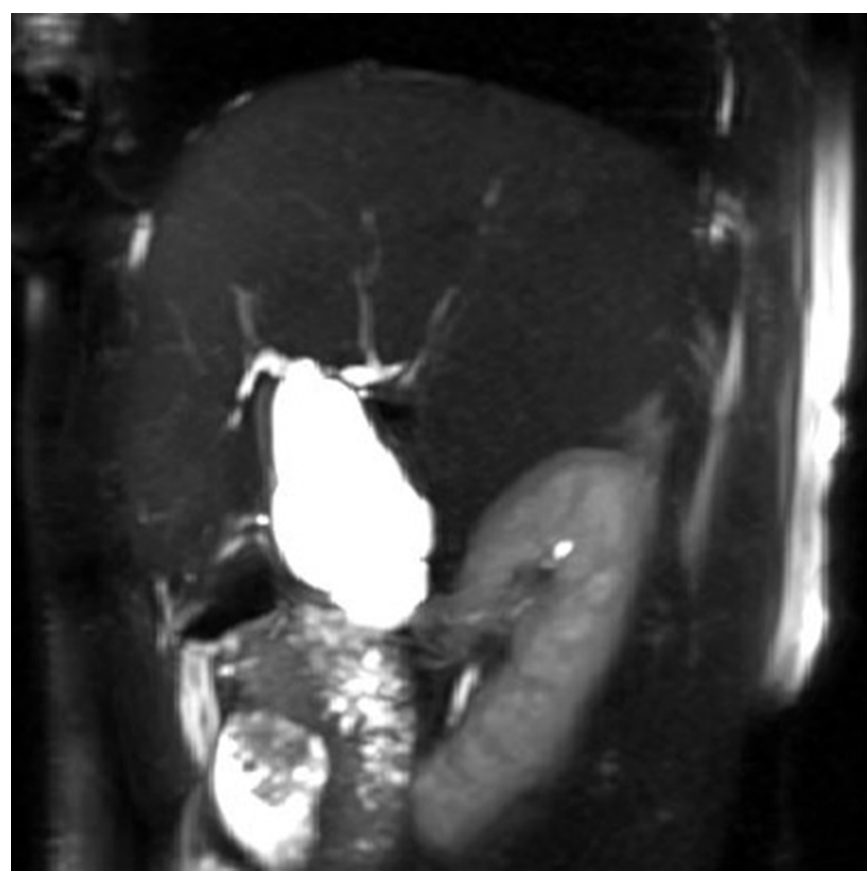

Figure 1. Dilatation of the choledochus (MR cholangiography).

\section{Discussion}

Although the choledochal cyst was first noticed early in the $18^{\text {th }}$ century, the first case in the literature was published in the $19^{\text {th }}$ century. In 1985 , Todani et al..$^{[4]}$ reported the classification of the lesions, which are defined as dilatation of the biliary tract. The most common types of choledochal cysts that are divided into five types are Types 1 and 4. Radiological examination is essential for both in the diagnosis and determination of the cyst type. ${ }^{[5]}$ Type 1 and type 4 choledochal cysts, require surgical treatment for prophylactic purposes. With the extend of minimally invasive methods, choledochal cyst excision and reconstruction has been started to be done by laparoscopic methods. ${ }^{[6]}$

In the study of Liem et al. ${ }^{[7]}$ The rate of conversion to open surgery was only $0.6 \%$ in 616 laparoscopic and open group

Table 1. The details of literature review

\begin{tabular}{lcccccc} 
Author & Year & Country & Period & Age & No & Biliary malignancy \\
\hline Palanivelu & 2008 & India & $1996-2008$ & 26.5 & 35 & 3 \\
Hwang & 2012 & South Korea & $2009-2011$ & $37.8 \pm 11.1$ & 20 & 0 \\
Jang & 2013 & China & $2003-2011$ & $32.7 \pm 13.9$ & 82 & 1 \\
Liu & 2014 & China & $2007-2011$ & $24.2 \pm 8.3$ & 35 & 0 \\
Duan & 2015 & China & $2009-2013$ & $23(18-30)$ & 31 & 0 \\
Nag & 2017 & India & $2011-2016$ & $45.5 \pm 11.4$ & 20 & 1 \\
Gundogan & 2018 & Turkey & $2013-1018$ & $41.5(22-49)$ & 8 & 1 \\
Total & & & & & 231 & $6(2.6 \%)$ \\
\end{tabular}


comparison study. In Diao et al.' $\mathrm{s}^{[8]}$ study; biliary leak was seen in $2 \%$ in laparoscopic group and $11 \%$ in open group. Contrary to our expectations, the biliary leak was more common in the open group. This difference is due to the fact that the increasing laparoscopic technical skills and the magnification advantage of laparoscopic surgery. Although our case were completed laparoscopically, we converted to open surgery to avoid an unsafe anastomosis. Comparative studies reported that; laparoscopic surgery did not have a disadvantage over open surgery, even the length of hospital stay and the need for reoperations were significantly lower. ${ }^{[7,8]}$ There were also publications showing that robotic surgery of minimally invasive surgical methods increases the safety of anastomosis of hepaticojejunostomy and reduces the rate of convertion to open surgery. ${ }^{[9]}$

In choledochal cysts, the likelihood of developing biliary cancer increases with age. Cancer risk in under 10 years is below $1 \%$, but $35 \%$ over $60 .{ }^{[10,11]}$ The most frequent site of malignancy is the cyst epithelium, the second is the gallbladder. The risk of malignancy at the gallbladder was previously considered a contraindication to laparoscopic surgery. The primary drawbacks were tumor spread due to gallbladder perforation and inadequate oncological surgery ${ }^{[12]}$ With the development of minimally invasive surgery and the increase in experience, this contraindication has begun to disappear. In the last decade oncologic results with open surgery, let the laparoscopic tecnique as an acceptable alternative. ${ }^{[13]}$

So far, we operated eigth adult choledochal cysts by laparoscopy and only in one case we identified a malignancy and we reported it here. The details of the remaining literature review was summarized in Table 1. Palanivelu ${ }^{[14]}$ reported three convertions all were done because there was suspicion of malignancy. Two patients had a mass at the junction of the cystic duct and the cyst wall. Cyst excision and removal of regional lymph nodes were performed. Histopathology revealed cholangiocarcinoma

with negative margins and nodes. These two patients had survived disease-free for 23 months. The third patient had a large choledochal cyst that extended up to the ampulla, replacing the entire pancreatic parenchyma. It was decided that the patient would need a Whipple's resection to remove the cyst in toto, so they performed it after conversion. Jang et al. ${ }^{[15]}$ reported a 37-year-old female presented for regular follow-up after the excision of a laparoscopic choledochal cyst (type Iva). A pancreatic head mass was detected after 39 months and pancreaticoduodenectomy with SMV resection was performed. She got postoperative chemotherapy and was disease free for 36 months. Recently Nag reported ${ }^{[16]}$ one patient detected to have gallbladder cancer on a suspicious mucosal lesion on inspection of gall bladder specimen and this patient finally underwent radical cholecystectomy with choledochal cyst excision. The incidence of biliary cancer in 231 laparoscopic adult choledochal cyst was $2.6 \%$ (Table 1). ${ }^{[14-19]}$

\section{Conclusion}

Choledochal cyst is a rare premalignant disease and it should be kept in mind that malignancy may accompany in laparoscopic resection of choledochal cyst, especially in adults.

\section{Disclosures}

Informed Consent: Written informed consent was obtained from the patient for the publication of the case report and the accompanying images.

Peer-review: Externally peer-reviewed.

Conflict of Interest: None declared.

\section{References}

1. Dhupar R, Gulack B, Geller DA, Marsh JW, Gamblin TC. The changing presentation of choledochal cyst disease: an incidental diagnosis. HPB Surg 2009;2009:103739. [CrossRef]

2. Todani $T$, Watanabe $Y$, Narusue $M$, Tabuchi $K$, Okajima $K$. Congenital bile duct cysts: Classification, operative procedures, and review of thirty-seven cases including cancer arising from choledochal cyst. Am J Surg 1977;134:263-9.

3. Dabbas N, Davenport M. Congenital choledochal malformation: not just a problem for children. Ann R Coll Surg Engl 2009;91:100-5. [CrossRef]

4. Todani T, Watanabe Y, Fujii T, Toki A, Uemura S, Koike YL. Cylindrical dilatation of the choledochus: a special type of congenital bile duct dilatation. Surgery 1985;98:964-9.

5. Suma S, Celenk C, Polat P, Tanı V, Eren S, Okur A. Choledocal cysts: two case reports. Ann Med Res 1996;3:223-5.

6. Kayaalp C, Soyer V, Ersan V, Aydın C, Karagul S. Laparoscopic choledochal cyst excision and Roux-en-Y hepaticojejunostomy. Turk J Surg 2015;32:152-4. [CrossRef]

7. Liem NT, Pham HD, Vu HM. Is the laparoscopic operation as safe as open operation for choledochal cyst in children? J Laparoendosc Adv Surg Tech A 2011;21:367-70. [CrossRef]

8. Diao M, Li L, Cheng W. Laparoscopic versus open roux-en-y hepatojejunostomy for children with choledochal cysts: intermediate-term follow-up results. Surgical Endoscopy 


\section{1;25:1567-73. [CrossRef]}

9. Peker YS, Urkan M, Oztas M, Can MF, Gulcelik MA. Robotic choledocal cyst resection and hepaticojejunostomy in a case with an aberrant hepatic artery coursing over the gall bladder. Laparosc Endosc Surg Sci 2018;25:37-40. [CrossRef]

10. Sastry AV, Abbadessa B, Wayne MG, Steele JG, Cooperman AM. What is the incidence of biliary carcinoma in choledochal cysts, when do they develop, and how should it affect management? World J Surg 2015;39:487-92. [CrossRef]

11. Andsay $N$, Klimstra D. Bening and malignant tumors of the gallbladder and the extrahepatic biliary track. Surgical Pathology of the GI Tract, Liver, Biliary tract, and Pancreas. Philadelphia: Sauners Elsevier; 2009. p. 845-75. [CrossRef]

12. Altuntas YE, Oncel M, Haksal M, Kement M, Gundogdu E, Aksakal N, et al. Gallbladder perforation during elective laparoscopic cholecystectomy: Incidence, risk factors, and outcomes. North Clin Istanb 2018;5:47-53. [CrossRef]

13. Zhang L, Hou C, Xu Z, Wang L, Ling X, Xiu D. Laparoscopic treatment for suspected gallbladder cancer confined to the wall: a 10-year study from a single institution. Chin J Cancer Res 2018;30:84-92. [CrossRef]

14. Palanivelu C, Rangarajan M, Parthasarathi R, Amar V, Senthil- nathan P. Laparoscopic management of choledochal cysts: technique and outcomes-a retrospective study of 35 patients from a tertiary center. J Am Coll Surg 2008;207:83946. [CrossRef]

15. Jang JY, Yoon YS, Kang MJ, Kwon W, Park JW, Chang YR, et al. Laparoscopic excision of a choledochal cyst in 82 consecutive patients. Surg Endosc 2013;27:1648-52. [CrossRef]

16. Nag HH, Sisodia K, Sheetal P, Govind H, Chandra S. Laparoscopic excision of the choledochal cyst in adult patients: An experience. J Minim Access Surg 2017;13:261-4. [CrossRef]

17. Liu Y, Yao X, Li S, Liu W, Liu L, Liu J. Comparison of therapeutic effects of laparoscopic and open operation for congenital choledochal cysts in adults. Gastroenterol Res Pract 2014;2014:670260. [CrossRef]

18. Duan X, Mao X, Jiang B, Wu J. Totally laparoscopic cyst excision and Roux-en-Y hepaticojejunostomy for choledochal cyst in adults: a single-institute experience of 5 years. Surg Laparosc Endosc Percutan Tech 2015;25:e65-8. [CrossRef]

19. Hwang DW, Lee JH, Lee SY, Song DK, Hwang JW, Park KM, et al. Early experience of laparoscopic complete en bloc excision for choledochal cysts in adults. Surg Endosc 2012;26:3324-9. [CrossRef] 